\title{
Captive breeding and trial reintroduction of the Endangered yellow-spotted mountain newt Neurergus microspilotus in western Iran
}

\author{
Mozafar Sharifi* ${ }^{*}$, Somaye Vaissi \\ Razi University Center for Environmental Studies, Department of Biology, Baghabrisham, 6714967346, Kermanshah, Iran
}

\begin{abstract}
The yellow-spotted mountain newt Neurergus microspilotus (Caudata: Salamandridae) is listed as Endangered by the International Union for Conservation of Nature. In spite of its conservation status and laws protecting it, the species continues to decline in the wild. A captive breeding program was successfully established to support the species' recovery. To learn more about the species' ecology and winter mortality, 24 juveniles reared in captivity were released on 4 occasions in a small spring enclosure from July to September 2012 and monitored until December, when they disappeared for overwintering. In 12 visits to the site before and after overwintering, a total of 31 individuals were identified. Based on an average diurnal detection probability for this newt $(0.61 \pm 0.19 \mathrm{SD})$, the observed newts during the pre-overwintering period were estimated to represent 6.5 to $41.0 \%$ of the reintroduced newts. The newts observed after overwintering were 13 to $28 \%$ of the reintroduced newts. This study demonstrates that post-metamorph captive-bred $N$. microspilotus released into the wild can survive to the second growing season, and provides a choice of life stage for a reintroduction plan.
\end{abstract}

KEY WORDS: Neurergus microspilotus · Endangered species · Captive breeding · Trial reintroduction

Resale or republication not permitted without written consent of the publisher

\section{INTRODUCTION}

Although the value of captive breeding and subsequent reintroduction as a conservation tool for threatened species remains controversial (e.g. Griffiths \& Pavajeau 2008), there are situations in which this is the only conservation option available for a threatened species (Stuart et al. 2004). The problems associated with captive breeding for release include rapid adaptation to captive life, genetic and demographic bottlenecks linked to the small founder population that may result in inbreeding depression, potential risks to the wild population from the collecting of founders for a captive population, and potential impacts on natural selection processes (Gilligan \& Frankham 2003). Furthermore, release of captive- bred animals to the wild requires implementation of protocols for genetic management, acclimation to new environments, pre-release health screening, and long-term post-release monitoring. Debates over the significance of captive breeding and subsequent reintroduction of endangered species as a conservation tool will continue (Armstrong \& Seddon 2008), but in light of the increasing pressures on wild amphibians globally, we cannot afford to exclude this practice from the 'tool box' (Griffiths \& Pavajeau 2008).

There are several life history traits in amphibians that make them ideal organisms for captive breeding and reintroduction (Jones 2002). High fecundity, rapid growth, small body size, and low maintenance requirements can lead to rapid establishment of cap- 
tive populations (Balmford et al. 1996, Kinne 2006). In recent years, captive breeding and subsequent reintroduction of amphibian species has increased in response to expanded knowledge of species under threat and growth in captive management capability (e.g. Fischer \& Lindenmayer 2000). With some 32\% of amphibian species threatened with extinction, there is an urgent need for various tools to address the global amphibian crisis (Stuart et al. 2004, IUCN 2011). Within the recently published Amphibian Conservation Action Plan, captive breeding and reintroduction form 2 out of the 11 priority actions for amphibian conservation and research (Gascon et al. 2007, IUCN 2011).

Three species of the genus Neurergus have been reported from Iran: $N$. crocatus, $N$. microspilotus, and $N$. kaiseri. Field investigations have confirmed that $N$. microspilotus occurs in several highland streams in the mid-Zagros range, but that it is highly vulnerable to the changes occurring in these areas (Sharifi \& Assadian 2005). The northernmost species of the genus Neurergus, including $N$. microspilotus and $N$. crocatus, are similar in general appearance, with dark-colored bodies covered in bright yellow spots. The dorsal spots of $N$. microspilotus are smaller than those of $N$. crocatus. The spots are found from the head to the tip of the tail, including the limbs, head, and flanks. N. microspilotus is listed as a Critically Endangered species by the International Union for Conservation of Nature (IUCN) (Red List criteria: A3cde+4cde; B2ab (iii, iv, v) ver 3.1) because of its very small area of occupancy $\left(<10 \mathrm{~km}^{2}\right)$, very limited fragmented habitats and a continuing decline in the extent and quality of its stream habitat, reduced number of subpopulations and individuals due to habitat degradation, drought, and over-collection of animals for both the national and international pet trade (Sharifi et al. 2009, IUCN 2011). The breeding habitat of N. microspilotus in the Zagrosia Oak Forest of the Zagros Mountains has recently been impacted by water pollution, water abstraction, and severe droughts, which has led to the extirpation of some populations. Extraction of stream water into nearby orchards is a major threat to this species (Sharifi et al. 2009, IUCN 2011).

Similar to many other amphibian species which face immediate threats to their survival, one possibility for Neurergus microspilotus in the short term is a rescue plan for the establishment and management of captive assurance colonies. Captive breeding and subsequent reintroduction of $N$. microspilotus may not be the final solution to conservation of this species, but, given the present circumstances, it may be the only chance to ensure the option of eventual recovery of the species in the future. A conservation action plan for $N$. microspilotus requires research on development of suitable husbandry and captive breeding protocols, disease control, development of captive management expertise, and mitigation of threats in the wild (Claude et al. 2005). Moreover, the existence of a captive breeding program for $N$. microspilotus will also facilitate basic research on other Iranian amphibians, including 2 Critically Endangered species: the Kaiser's mountain newt $N$. kaiseri and the Gorgan Mountain salamander Paradactylodon gorganensis.

Captive breeding and reintroductions to the wild have become an important tool in species conservation programs (Frankham et al. 2010). These programs aim to re-establish a self-sustaining population of a species in an area where the species was formally extant. However, implementation of a conservation translocation of captive-bred individuals of an endangered species extends beyond the release of organisms (IUCN 2011). According to IUCN guidelines for reintroduction programs, including those to a highly suitable area, these programs can fail because many elements of the programs are poorly designed, eg pre-release factors (such as feasibility and habitat studies), post-release monitoring, regulatory compliance, and resource availability (Soorae 2010). Therefore, there should be a greater emphasis on the fact that the major problem in reintroduction plans is understanding the ecological requirements of the species so that populations can be restored in the future. This study aimed to contribute to conserving a threatened species, the yellow-spotted mountain newt Neurergus microspilotus, through a trial reintroduction, and to provide basic data to evaluate the status of the released individuals.

In 2010, the Mohamed bin Zayed Species Conservation Fund helped to develop and implement a conservation management plan for the yellow-spotted mountain newt. Part of this plan included the development of a captive breeding facility at Razi University, Kermanshah, Iran. The ultimate goal of the captive breeding program is to provide stock and increase the species' population size across different breeding streams to ensure their long-term survival. Captive-bred individuals are intended for use to either supplement wild populations to a self-sustaining level or to re-establish this species in parts of its former range. The captive breeding program has been successful, with the captive population size increasing each year, including newts from a stream that was previously assumed locally extinct (Sharifi \& 
Assadian 2004). The present trial release allowed us to improve techniques that could ultimately maximize the success of any potential future reintroduction. A trial release of captive-raised yellow-spotted mountain newts is important because it provides information on (1) the extent to which these newts are able to survive in their natural habitat, (2) whether they will remain at the release site in their second year, (3) whether they will return to the site of release following their terrestrial foraging and begin reproduction in their third year of age, and (4) whether reintroduction is an effective conservation strategy by establishing a viable population at the release site.

\section{MATERIALS AND METHODS}

\section{Captive breeding}

The captive breeding facility (CBF) is a $5 \mathrm{~m}$ long $\times$ $2.5 \mathrm{~m}$ wide $\times 3 \mathrm{~m}$ high room at Razi University, Kermanshah, Iran; Fig. 1. Additional space was available for eggs and larvae in an ecology laboratory at the Department of Biology, Razi University. The CBF was ventilated by an air conditioner that re-circulated the indoor air. Ten aquaria, each $75 \times 25 \times 40 \mathrm{~cm}$ (length $\times$ width $\times$ height), were located on metal racks. Each had an individual electrical water pump and waste pump, and water temperature in summer was in the range 15 to $24^{\circ} \mathrm{C}$. Each aquarium included terrestrial habitat in the form of small pebbles collected from the wild. Food comprised blood worms Glycera dibranchiata and live mealworms Teneberio molitor. We placed up to 9 to 12 mature newts together in 1 aquarium with a sex ratio of 2 males to 1 female. The aquaria contained some aquatic plants for egg attachments and hiding opportunities.

For the reintroduction, the largest individuals of similar age ( 5 to $7 \mathrm{mo}$ ) newts were considered to be of sufficient size to withstand predation by crabs Potamon bilobatum, toads Bufo bufo, and water snakes Natrix natrix. In addition, they should have achieved a sufficiently advanced stage of larval development to be able to optimize their resistance to environmental factors. Post-metamorphic juveniles were released in the spring enclosure on 4 occasions (6 individuals per occasion) in 2012: 20 July, 31 August, 14 September, and 28 September. Average snout-tovent length of these individuals was 22.58, 25.00, 35.20, and $34.70 \mathrm{~mm}$, respectively. All individuals had been maintained in the captive conditions described above for all of their life. The sex of these newts was not known at the time of release. All were siblings of 2 females and 4 males collected from Ghorighalah Stream. The newts selected for the trial reintroduction were given a visual health screening (skin slough, wound) and behavioral examination (viability and responsiveness to stimulus) to ensure they were healthy. The probability of released newts contracting an infection was considered very low because the release was planned for a site that no longer contained free-ranging newts.

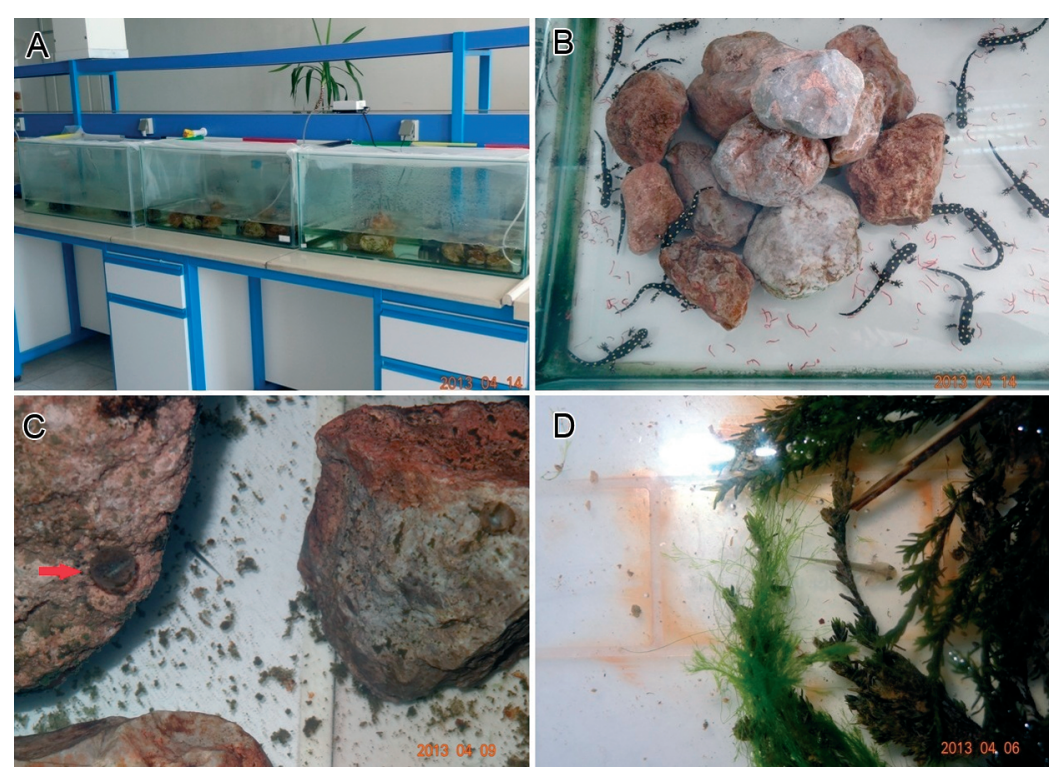

Fig. 1. Neurergus microspilotus. The captive breeding facility at Razi University, Kermanshah, Iran. (A) aquaria, (B) N. microspilotus feeding on blood worms, (C) eggs attached to the stones (red arrow), and (D) newly hatched larvae

\section{Reintroduction}

The suitability of different potential reintroduction sites was assessed against several criteria, i.e. degree of isolation from human settlements, proximity to a benthic macroinvertebrate community, submerged vegetation cover, water temperature, altitude, and land use along the stream. We examined the morphology of springs and streams, as well as their vegetative composition and structure. For identification purposes, before release each individual was photographed using a fixed tripod to record the individual distribution pattern of the yellow spots on the head and shoulders. This was based on the photographic identification procedure 
used for this species (Sharifi et al. 2013). The introduced juveniles were fed benthic macroinvertebrates by translocating benthic materials to the enclosure and by inserting live mealworms Teneberio molitor into fissures of wood logs placed into the water and other cavities within the enclosure.

The reintroduction site was monitored on 12 occasions: 20 July, 31 August, 14 September, 28 September, 19 October, 2 November, 16 November, and 30 November in 2012, and 12 March and 9 April in 2013. Two visits in December 2012 and January 2013 resulted in no observation of Neurergus microspilotus because of severe freezing. We searched the spring within the enclosure and the outlet of the spring, which merged with Mivan Stream 50 m downstream. At the site and along the outlet, we (authors and volunteer postgraduate students, with at least 3 present for each survey) searched for and counted N. microspilotus within the stream enclosure and along the stream banks during the day, usually between 10:00 and 13:00 h. We investigated crevices under loose rocks and in bedrock to find sheltering animals. We also looked for resting individuals in tall grasses, sedges, and rocks near the water's edge.

\section{Detection probability}

To examine the strength of the unadjusted count data obtained in the regular visits to the reintroduction site, and to prevent the generation of a false population estimate, we used the detection probability determined for Neurergus microspilotus in Kavat Stream (M. Sharifi \& B. Naderi unpubl.). These authors estimated the detection probability of adult $N$. microspilotus in 4 isolated small pools with a constant number of the newts separated from the main stream by stones. In 72 visual encounter surveys to these pools, detection probability was derived from average hourly detection probability according to the survey duration. We avoided direct measurement of detection probability at the Mivan Spring enclosure because we did not want to disturb the released newts.

The average detection probability was then used to adjust visual counts as follows (Bailey et al. 2004):

$$
N=C / \beta
$$

where $C=$ number of individuals counted, $\beta=$ probability of detection, and $N=$ adjusted visual count.

\section{RESULTS}

\section{Captive breeding}

In the $\mathrm{CBF}$, embryonic development (from oviposition to hatching) took $28 \mathrm{~d}$. The diameter of freshly laid eggs ranged from 6.97 to $9.47 \mathrm{~mm}$ (Table 1). Larvae freshly hatched in early April measured from 13.08 to $14.94 \mathrm{~mm}$. Immediately after hatching, the first larvae began moving in the aquarium. They attached with their mouth parts to stones, plant material, and the glass of the aquarium. They remained largely motionless and consumed their internal nutrient reserves. Approximately 1 mo after hatching, the larvae were fed small cultured Artemia twice a week. After 5 mo they measured 41.54 to $53.15 \mathrm{~mm}$ total length. Most of the time, the larvae drifted almost motionless but sometimes darted forward to catch a passing planktonic organism. To prevent egg or larvae cannibalism by adult $N$. microspilotus, eggs were transferred to separate aquaria. At about $7 \mathrm{wk}$, the first pigment spots appeared on the body of the larvae.

\section{Growth and development}

The various stages for Neurergus microspilotus metamorphosis in the CBF are shown in Fig. 2. There is no information available on growth and development of $N$. microspilotus during the period between the end of metamorphosis and the attainment of sexual maturity. Metamorphosed juveniles of N. microspilotus begin to stay more in the terrestrial component of their habitat at a body length of 70.13 to $78.09 \mathrm{~mm}$. In the field during growth to maturity, subadults of yellow-spotted newts occasionally return to aquatic life (authors' pers. obs.). In captivity, sexual maturity was not attained in the second year after hatching. The reproductive cycle of N. microspilotus based on reproductive events observed in the $\mathrm{CBF}$ is shown in Fig. 3. In the CBF, they ate Artemia at 1 mo,

Table 1. Neurergus microspilotus. Size of freshly laid eggs and total length of $1 \mathrm{~d}$ old larvae, juveniles (without branchia, 6 mo old) and sub-adults (post-metamorphs, 12 mo old). n: no. of samples

\begin{tabular}{|lcc|}
\hline & $\mathrm{n}$ & Mean \pm SD (mm) \\
\hline Gelatinous layer diameter & 50 & $8.22 \pm 1.35$ \\
Egg diameter & 50 & $3.70 \pm 0.52$ \\
Total length of larvae & 10 & $14.01 \pm 0.92$ \\
Juveniles (without branchia, 6 mo old) & 80 & $67.07 \pm 5.67$ \\
Sub-adults (post-metamorphs, 12 mo old) & 50 & $88.80 \pm 3.18$ \\
\hline
\end{tabular}


followed by Glycera dibranchiata and live Teneberio molitor during pre- and post-metamorphosis.

\section{Site selection for reintroduction}

Nine water bodies (springs, streams, and karst seepage) were initially examined for the reintroduction site. Of these, 5 were identified as potential reintroduction sites based on their degree of isolation from human settlements, proximity to a benthic macroinvertebrate community, submerged vegetation cover, water temperature, altitude, and land use along the stream. We also only selected sites that were in the tributaries of the KavatGhorighala-Gholani catchment area, where the original founder population was collected, so that any successfully recruited newts would remain in the distribution range of the Kavat-Ghorighala-

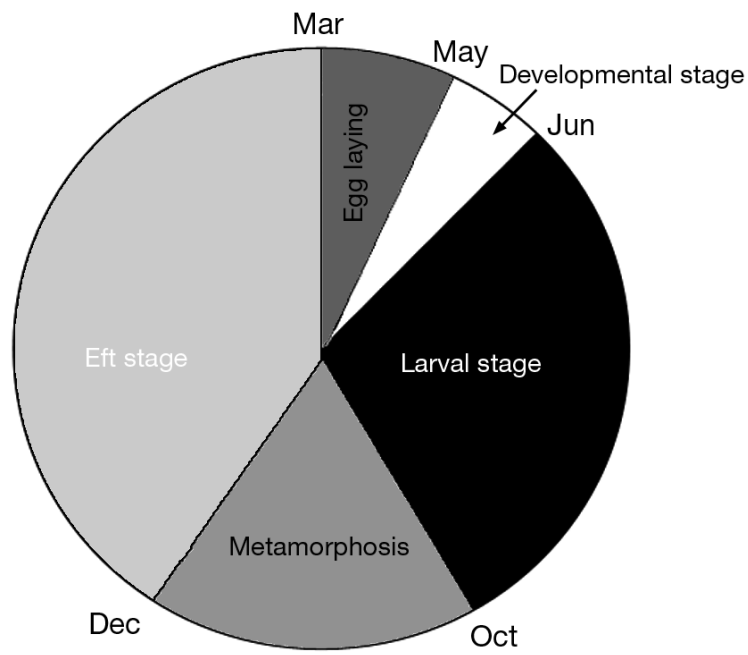

Fig. 3. Neurergus microspilotus. Reproductive cycle based on reproductive events observed in the captive breeding facility
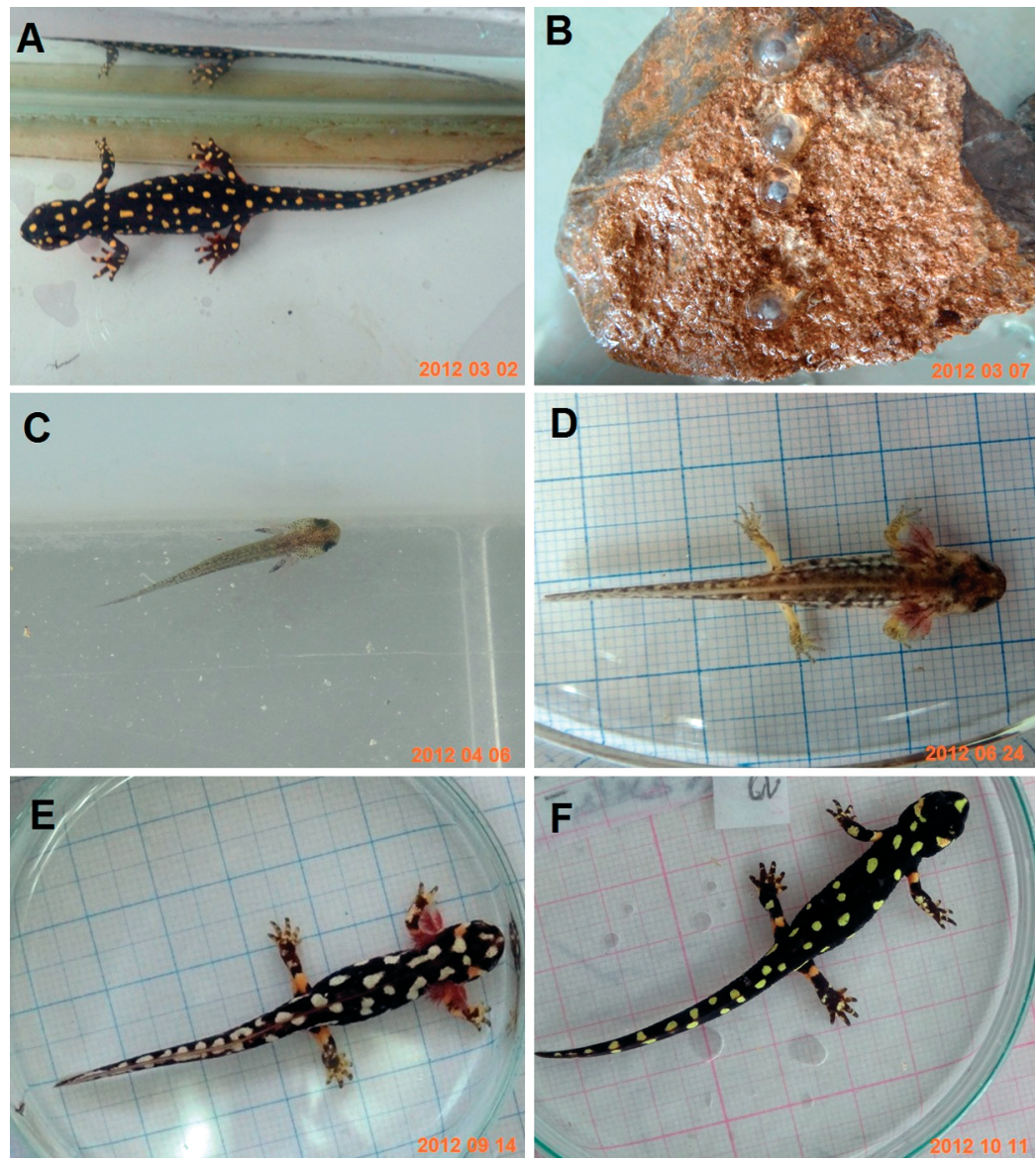

Fig. 2. Neurergus microspilotus. Metamorphosis occurring in the captive breeding facility. (A) Mature female with swollen abdomen ready to lay eggs, (B) newly laid eggs (on the stone), (C) 2 d old larva, (D) 7 wk old larva, (E) 5 mo old larva, and (F) fully grown young-of-the year without the gill branchia
Gholani population. Based on the assessment of these criteria for each water body, Mivan Spring was chosen for the present trial reintroduction (Table 2).

\section{Monitoring}

The Mivan Spring enclosure is a small room $(2 \times 2 \times 1 \mathrm{~m})$ constructed over a spring with a water discharge of about $10 \mathrm{l} \mathrm{s}^{-1}$. This spring immediately joins Mivan Stream, which contains well-developed submerged and periphyton vegetation (e.g. species of Elodea, Myriophyllum, Veronica, and several species of mosses). Along the stream there are also well-established emergent and marginal plant associations. In 12 visits to the site before and after overwintering, a total of 31 individual newts were identified (Table 3 ). Two visits in December 2012 and January 2013 resulted in no observation of $N$. microspilotus because of severe freezing. The number of newts expected at every visit to the Mivan Spring is the product of the proportion of the individuals observed and the average probability of detection. Based on the detection probability for Neurergus microspilotus in Kavat 
Table 2. Summary of sites surveyed for their isolation, land use, presence of potential predators (Buffo buffo, Natrix natrix), altitude (Alt, m), and benthic macroinvertebrates (food). UTM: Universal Transverse Mercator coordinate system, an international locational reference system that depicts the Earth's 3-dimensional surface in a relatively accurate, 2-dimensional manner

\begin{tabular}{|lccccccc|}
\hline Site & UTM & Alt & Isolation & Land use & B. buffo & N. natrix & Food \\
\hline Ghorighala & $37519589 / 386132028$ & 1600 & Inadequate & Forest & Present & Present & Adequate \\
Bezreh & $63622720 / 386020689$ & 1600 & Lacking & Forest & Present & Present & Inadequate \\
Lorabi & $63169941 / 386139451$ & 1400 & Inadequate & Forest & Present & Present & Inadequate \\
Lameh Olia & $63014067 / 386733259$ & 1550 & Lacking & Forest & Present & Present & Inadequate \\
Mivan & $62939840 / 387163770$ & 1650 & Safe & Range & Absent & Absent & Adequate \\
\hline
\end{tabular}

Stream (Sharifi et al. in press), on average, any visual observation may have a $0.61 \pm 0.21(\mathrm{SD})$ detection probability. Therefore, the count data of the reintroduced $N$. microspilotus in Mivan Stream was adjusted to percent survived (Table 3 ).

\section{DISCUSSION}

This trial reintroduction was an intentional release of captive-bred individuals inside their indigenous range. Our ultimate objective was to determine not only an optimum choice of life stage for a reintroduction program but also an optimal size and age based on a cost-effective evaluation of the reintroduction to the wild. This study highlights the importance of understanding the survival rates of post-metamorph newts and their potential role in a possible reintroduction program, as this species is long-living species that may reach maturation in its third or fourth year of age (Sharifi et al. 2014). The present trial reintroduction demonstrated that young-of-the-year captive-bred Neurergus microspilotus released into the wild can survive to the second growing season and may be a choice for a reintroduction plan. Observed

Table 3. Neurergus microspilotus. Date and number of the post-metamorphs reintroduced to the Mivan Stream, number of individuals observed before and after overwintering, percent of individuals observed before and after overwintering, and an estimate of the survival of newts based on detection probability

\begin{tabular}{|lcccc|}
\hline Date & No. released & No. observed & \% observed & \% survived \\
\hline 20-Jul-12 & 6 & 0 & 0 & 0 \\
31-Aug-12 & 12 & 3 & 50 & 82 \\
14-Sep-12 & 18 & 5 & 42 & 69 \\
28-Sep-12 & 24 & 4 & 22 & 46 \\
19-Oct-12 & 0 & 1 & 4 & 6.5 \\
02-Nov-12 & 0 & 6 & 25 & 41 \\
16-Nov-12 & 0 & 1 & 4 & 6.5 \\
30-Nov-12 & 0 & 5 & 21 & 34.4 \\
12-Mar-13 & 0 & 2 & 8 & 13.1 \\
9-April-13 & 0 & 4 & 17 & 28 \\
\hline
\end{tabular}

post-overwintering visual counts (Table 2) gave an estimated average survival rate of $20.5 \%$ of the total number reintroduced. This comparatively high rate of survivorship of the released juveniles is partly attributable to the relatively protected enclosure, which probably reduced the impact from native predators. This preliminary result suggests that an expensive control of predator populations before large-scale releases may not be required. The experiment also demonstrates that it may be more effective to release post-metamorph rather than adult newts. The slow growth rate of $N$. microspilotus and relatively late age of sexual maturation at 3 or 4 years means that newts would have to be maintained in captivity for a longer period, if it was found desirable to release them at the adult stage. However, maturation at age 3 or 4 slows down the build-up of stock available for a reintroduction and increases the expenditure per released newt. Moreover, in the case of a very long captive period, especially if individuals become mature in the captivity, adaptation to the captive life may cause negative impacts on the fitness of the reintroduced individuals.

Because of the lack of information on life history and ecology of Neurergus microspilotus, there are few generalizations demonstrating the relationships between habitat correlates and $N$. microspilotus abundance that can be used in laying down the process for reintroduction. From 14 known stream habitats for this newt, only 2 streams may have population sizes of more than a few hundred individuals. The remaining habitats contained few to tens of individuals (M. Sharifi \& B. Naderi unpubl.). Studies on some amphibian communities have shown that abundance and species richness are negatively correlated with low temperatures, low $\mathrm{pH}$, and high conductivity (e.g. Okonkwo 2011). Some streams in the study area, including the 2 sites with the highest populations, were 
found to be have low conductivity, very low turbidity, and moderate $\mathrm{pH}$ (Sharifi \& Assadian 2004). However, both of these streams are located in a cold climate zone within the species' range. Water temperatures influence both breeding timing and speed of development to metamorphosis (Okonkwo 2011). Cold water temperatures may delay breeding, leaving a shorter time available for young-of-the-year to grow before overwintering. It has been documented for several ranids that late metamorphosing individuals have a lower survival rate and do not grow as quickly as those who metamorphosed earlier (e.g. Altwegg \& Reyer 2003).

Mivan Stream as a potential site for reintroduction of Neurergus microspilotus was selected based on a group of criteria to determine suitability for receiving founder stock. Most importantly, selection of this site was based on the degree of protection it afforded from predators, on its close vicinity to a macroinvertebrate community, its high altitude and cold water, isolation from human disturbance, and relative security from current and future habitat threats which might result from land-use alteration. This selection process maximized the suitability of the release site to the aquatic environment occurring within a relatively short distance of desired source populations and within the same watershed. This study presents a multicriteria decision analysis approach for selecting a reintroduction site for the yellow-spotted mountain newt. This approach enabled us to evaluate the relative importance of various potential sites using an expert opinion approach involving a set of perceived species preferences and threat criteria, which led to an evaluation of the suitability of the study region to define a reintroduction site.

Data collected on the number of newts during the pre- and post-reintroduction periods are unadjusted count data and may not represent the population density because detection probability has not been determined at the release site. Such data can be adjusted if an estimate of detection probability can be provided. We avoided direct measurement of detection probability in the small enclosure over the reintroduction site because we did not want to disturb the released newts. Moreover, such measurement involving a small number of newts may result in a biased detection probability. Detection probability of adult Neurergus microspilotus used in the present study has been measured in Kavat Stream (Sharifi et al. in press), about $10 \mathrm{~km}$ away from Mivan Stream. As detection probabilities only use values between 0 and 1 (Schmidt 2003), count data on the number of $N$. microspilotus sighted during pre- and post-reintro- duction periods are likely to provide an underestimate of the true population abundance.

Neurergus microspilotus occurs in 2 distinct climatic regimes: cold and wet in the highlands of the Zagros Range and warm and dry at low elevation in Iran and Iraq. The climate of the western edge of the Iranian Plateau in the mid-Zagros Range is characterized by pronounced seasonal variation, including a long period of constant sub-zero temperatures in winter and a mild summer. At the closest metrological station to Kavat Stream, at an elevation of $1200 \mathrm{~m}$ (450 m lower than the study site), there is over 2 mo of freezing. In the lowlands of the northern Mesopotamian Plain, where some parts are only 20 or $30 \mathrm{~km}$ away from the cold uplands, summer is hot and dry and winter has no freezing period (Sharifi \& Assadian 2004). As a result of the sharp climatic gradient at the edge of the Iranian Plateau, the prevailing climatic conditions are not only different between streams but also within streams. As these streams are located on the western edge of the Iranian Plateau, the climatic conditions may vary considerably between the upper reaches and the lower reaches of the same streams. At the same time, the streams closer to the Mesopotamian Plain experience climatic conditions that are different to the conditions experienced by streams located at the western edge of the Iranian Plateau. Recent large-scale water abstraction programs and damming have caused a shorter hydroperiod in the distribution range of $N$. microspilotus. Therefore any possible reintroduction program for this species should give high priority to the relatively more stable first-order streams in the highlands of the Zagros Range.

Acknowledgements. We thank the organizations that supported this study over the years, in particular, Razi University and the Iran National Science Foundation (Contract No. 91057277) that financially supported this study as a part of $\mathrm{PhD}$ research projects. We also appreciate support from the Mohamed bin Zayed Species Conservation Fund to set up the captive breeding facility for Neurergus microspilotus.

\section{LITERATURE CITED}

Altwegg R, Reyer HU (2003) Patterns of natural selection on size at metamorphosis in water frogs. Evolution 57:872-882

Armstrong DP, Seddon PJ (2008) Directions in reintroduction biology. Trends Ecol Evol 23:20-25

Bailey LL, Simons TR, Pollock KH (2004) Estimating site occupancy and species detection probability parameters for terrestrial salamanders. Ecol Appl 14:692-702

Balmford A, Mace GM, Leader-Williams N (1996) Designing the ark: setting priorities for captive breeding. Conserv Biol 10:719-727 
Claude G, Collins JP, Moore RD, Church DR, McKay JE, Mendelson III JR (2005) Amphibian conservation action plan. In: Gason C, Collins JP, Moore RD, Church DR, McKay Je, Mendelson III JR (eds) Proc IUCN/SSC Amphibia Conserv Summit, Chapter 7. IUCN, Gland, p 36-37

Fischer J, Lindenmayer DB (2000) An assessment of the published results of animal relocations. Biol Conserv 96: $1-11$

Frankham R, Ballou JD, Briscoe DA (2010) Introduction to conservation genetics, 2nd edn. University Press, Cambridge

Gascon C, Collins JP, Moore RD, Church DR, McKay JE, Mendelson JR III (2007) Amphibian conservation action plan. IUCN/SSC Amphibian Specialist Group, Gland

Gilligan DM, Frankham R (2003) Dynamics of genetic adaptation to captivity. Conserv Genet 4:189-197

Griffiths RA, Pavajeau L (2008) Captive breeding, re-introduction, and the conservation of amphibians. Conserv Biol 22:852-861

IUCN (International Union for Conservation of Nature) (2011) IUCN Red List of Threatened Species, version 2011.1 www.iucnredlist.org (accessed June 2013)

Jones CG (2002) Reptiles and amphibians. In: Perrow MR, Davy AJ (eds) Handbook of ecological restoration. Cambridge University Press, Cambridge, p 355-375

Kinne O (2006) Successful re-introduction of the newts Triturus cristatus and T. vulgaris. Endang Species Res 1: 25-40

Okonkwo GE (2011) The use of small ephemeral wetlands and streams by amphibians in the mixed wood forest of boreal Alberta. MSc thesis, University of Alberta, Edmonton

Editorial responsibility: Michael Mahony, Callaghan, New South Wales, Australia
Schmidt BR (2003) Count data, detection probabilities, and the demography, dynamics, distribution, and decline of amphibians. C R Biol 326 (Suppl 1):119-124

Sharifi M, Assadian S (2004) Distribution and conservation status of Neurergus microspilotus (Caudata: Salamandridae) in western Iran. Asiat Herpetol Res 10:224-229

Sharifi M, Assadian S (2005) Reproductive cycle of the yellow spotted newt Neurergus microspilotus (Caudata: Salamandridae) in western Iran. Russ J Herpetol 12: 63-68

Sharifi M, Bafti SS, Papenfuss T, Anderson S, Kuzmin S, Rastegar-Pouyani N (2009) Neurergus microspilotus. In: IUCN 2012: IUCN Red List of Threatened Species, version 2012.2, www.iucnredlist.org (accessed 23 April 2013)

Sharifi M, Naderi B, Hashemi R (2013) Suitability of the photographic identification method as a tool to identify the endangered yellow spotted newt, Neurergus microspilotus (Caudata: Salamandridae). Russ J Herpetol 20: 264-270

Sharifi M, Farasat H, Vaissi S, Parto P, Haghighi ZMS (2014) Prevalence of the amphibian pathogen Batrachochytrium dendrobatidis in Endangered Neurergus microspilotus (Caudata: Salamandridae) in Kavat Stream, Western Iran. Glob Veterinaria 12 (1):45-52

Soorae PS (2010) Global re-introduction perspectives: 2010 additional case-studies from around the globe. IUCN/ SSC Re-introduction Specialist Group. http://data.iucn. org/dbtw-wpd/edocs/2010-076.pdf (accessed June 2013)

Stuart SN, Chanson JS, Cox NA, Young BE, Rodrigues ASL, Fischmann DL, Waller RW (2004) Status and trends of amphibian declines and extinctions worldwide. Science 306:1783-1786

Submitted: April 29, 2013; Accepted: October 8, 2013 Proofs received from author(s): January 18, 2014 